\title{
MEDIAÇÃO E CONVERGÊNCIA EM BIBLIOTECAS ACADÊMICAS: saberes e práticas culturais
}

\author{
MEDIATION AND CONVERGENCE IN AN ACADEMIC LIBRARIES
}

\author{
Leilah Santiago Bufrem - leilah@ufpr.br \\ Doutora em Ciências da Comunicação pela USP \\ Professora Titular do Departamento de Ciência e Gestão da Informação \\ Universidade Federal do Paraná - Curitiba - PR \\ Tidra Viana Sorribas - tidra@ufpr.br \\ Bolsista de Iniciação Científica (PIBIC/CNPq) \\ Curso de Gestão da Informação da Universidade Federal do Paraná
}

\begin{abstract}
Resumo
Analisa as possibilidades de uma cultura informacional nas bibliotecas universitárias brasileiras para a construção de um ambiente propício à formação de saberes, estabelecendo cinco categorias relativas à problemática levantada: o contexto; os fenômenos da mediação e da convergência relacionados às bibliotecas acadêmicas; os sujeitos no processo; as relações de força e a articulação entre esses fatores. Conclui que as bibliotecas têm o poder de conjugar as práticas investigativas para a construção dos saberes, não apenas como integrantes da cultura universitária, mas como sujeitos de sua construção.
\end{abstract}

Palavras-chave: Bibliotecas universitárias. Mediação. Convergência. Redes de informação.

\section{INTRODUÇÃO}

Obedecendo ao princípio de que para assumir um tema instigante deve-se começar pela definição de um problema, questionam-se as possibilidades de uma cultura informacional nas bibliotecas universitárias brasileiras diante dos fenômenos da mediação e da convergência.

Para respondê-lo, opta-se neste artigo pela recuperação de reflexões anteriores de estudiosos da área. Recorre-se a uma questão chave, expressa por González de Gómez, a partir da premissa de que a Ciência da Informação inicialmente teve como campo temático a ciência, a tecnologia e os recortes institucionais da geração e uso da informação: como compreender os movimentos globalizados da transferência de informação, em oposição à multiplicação de um "diferencial pragmático" nos plurais espaços de comunicação? Como enfrentar o crescimento ilimitado da informação e da incomunicação? (1995, p. 78). 
Enfrenta-se, nessa busca, como contraponto à certeza sobre o papel determinante das tecnologias de informação para países recém industrializados, autores que as consideram como mecanismos reprodutores das desigualdades globais existentes (FURNIVAL, 1998). A concepção reprodutivista descende de posições representadas historicamente pelos seguidores da escola de Frankfurt, mas algumas de suas previsões são, pelo menos, postas em dúvida, como argumentam Santos e Martinez (2000, p. 111) sobre o futuro:

[...] com a crescente virtualização (tecnologia substituindo o espaço público da prática política), é que se mostrará se a democracia foi posta em rede (pública) ou se apenas foi "tecnologizada", tornando-se a imagem mais cara do conceito, ou seja, "publicidade". A articulação da idéia de rede com a experiência das bibliotecas públicas seria uma possibilidade na realização da interação social e na construção da cidadania.

É possível perguntar-se, entretanto, se práticas e estratégias como a mediação e a convergência estariam a serviço dos processos inclusivos de interação social e construção da cidadania, entendendo-se o primeiro termo em sua dimensão sócioeducacional e o segundo, numa perspectiva tecnológica. Questionam-se as possibilidades de uma cultura informacional nas bibliotecas universitárias brasileiras diante desses dois fenômenos e se é possível construir uma cultura investigativa em cenário de transformações aceleradas.

Apresenta-se, como propósito deste estudo, a exploração dos conceitos de mediação e convergência, focalizando-se o papel das bibliotecas universitárias nas práticas informacionais por eles influenciadas.

Como motivação, visualiza-se a possibilidade de um diálogo exploratório sobre as questões que envolvem o tema, ainda a ser fomentado, em prol da construção de um ambiente propício à formação de saberes. Desse modo, assume-se a biblioteca universitária como centro de cultura investigativa e de aprendizagem e o profissional bibliotecário como ator coadjuvante, mas privilegiado nesse ambiente. Defende-se, nessa linha de raciocínio, a necessidade da valorização da informação, do conhecimento e das TICs para a cultura acadêmica.

Uma busca preliminar sobre o tema na literatura brasileira em Biblioteconomia e Ciência da Informação (BCI), entre 4212 registros da base BRAPCI ${ }^{1}$, correspondentes a artigos de 26 periódicos² da área de Biblioteconomia e Ciência da Informação no Brasil,

1 Base de Dados Referenciais de Periódicos Nacionais da Área de Ciência da Informação.

2 Arquivística.net; Arquivo \& Administração; BIBLOS: Revista do Departamento de Biblioteconomia e História; Cadernos de Biblioteconomia; Ciência da Informação; Comunicação \& Informação; DataGramaZero; Em Questão: Revista da Faculdade de Biblioteconomia e Comunicação da UFRGS; Encontros Bibli; Estudos Avançados em Biblioteconomia e Ciência da Informação; ETD - Educação Temática Digital; Infociência; Informação \& Informação; Informação \& Sociedade: Estudos; Informare 
foram selecionados 537 sobre sistemas e/ou redes de informação, 24 contendo o termo mediação entre resumos e/ou descritores e 27 contendo o termo convergência. Devido à amplitude temática e à diversidade de descritores, foram estabelecidas cinco categorias de análise, inspiradas em Souza (2004) e cuja abrangência permitiu incluir entre elas os aspectos mais sugestivos relativos à problemática levantada:
a) o contexto;
b) os fenômenos da mediação e da convergência;
c) os sujeitos no processo, com destaque para alunos, profissionais bibliotecários, professores, especialistas, universidades e bibliotecas;
d) as relações de força e
e) a articulação entre mediação e convergência.

A adoção de pressupostos teóricos favorece a percepção do referencial que fundamenta este estudo, iniciando-se pela afirmação de que as bibliotecas universitárias não se constituem apenas em guardiãs, difusoras ou disseminadoras do saber, pois seus compromissos ampliam-se, abrangendo o aprender e o criar. Acredita-se que elas contribuem decisivamente para a construção de uma cultura investigativa, em que seja substituída a ênfase no ensino e na transferência, pela ênfase na aprendizagem. Para essa missão concorrem as redes de informação cooperativas e as estratégias tecnológicas sempre renovadas de informação e comunicação, além de fundamentos teóricos da proposta de ensino com pesquisa e de aprendizagem baseada em problemas.

A trajetória deste estudo parte da crença irrestrita na possibilidade de democratizar o saber e fundamenta-se na máxima de Gramsci (1988) de que difundir as verdades já descobertas, socializar essas verdades, socializar o novo, só é possível quando de fato a sociedade tem acesso ao saber. Mas esse saber, construído na história coletiva, está submetido a processos de validação, capitalização e transmissão, processos tão antigos quanto a escrita em suportes e que vêm servindo à humanidade para o aperfeiçoamento de práticas, a produção científica e os avanços tecnológicos. O saber só permanece válido, entretanto, se a comunidade científica o reconhecer como tal e se a sociedade continuar considerando tratar-se de um saber que tem valor e merece ser transmitido (CHARLOT, 2000).

E, para que se realize o processo de transmissão e consolidação dos saberes, destacamse, além das concepções teóricas, do planejamento e das práticas de ensino, os instrumentais da tecnologia, os quais, segundo uma concepção epistemológica aceita por autores contemporâneos, "ampliam o potencial cognitivo do ser humano" (ASSMANN, 2000, p. 9). Inspirados na capacidade de objetivação dos resultados dos

- Cadernos do Programa de Pós-Graduação em Ciência da Informação; Liinc em revista; Perspectivas em Ciência da Informação; Revista ACB: Biblioteconomia em Santa Catarina; Revista Brasileira de Biblioteconomia e Documentação; Revista da Escola de Biblioteconomia da UFMG; Revista de Biblioteconomia \& Comunicação; Revista de Biblioteconomia de Brasília; Revista Digital de Biblioteconomia \& Ciência da Informação; Revista do Departamento de Biblioteconomia e História; Revista Online da Biblioteca Prof. Joel Martins; Transinformação. 
processos cognitivos, esses autores concebem as suas demonstrações concretas como expressão do conhecimento adquirido. É nesse sentido que todas as facilidades advindas das redes virtuais distribuem-se em benesses aos internautas e o ciberespaço, segundo Oddone (1998), passando a proporcionar aos indivíduos autonomia com relação ao processo de busca.

Decorre dessas primeiras assertivas a convicção de que a transformação efetiva das bibliotecas é parcialmente derivada dos desenvolvimentos tecnológicos. Entretanto, eles não podem ser divorciados das "forças políticas e econômicas que dirigem a mudança tecnológica" (BIRDSALL, 2005, p. 86). Compatibilizando essa mobilização de forças, sobressaem as redes de informação como instrumentos mobilizadores desse processo de transformação das bibliotecas clássicas em centros de recursos para a aprendizagem. Aliando a tecnologia à criatividade, elas tornam-se elementos de articulação entre os processos de mediação e convergência.

Esse potencial de mobilização e autonomia individual ou institucional, proporcionado pelos instrumentos disponíveis, pode entretanto ser relativizado ou potencializado. Isso depende das condições dos processos com vistas à aprendizagem. Assim, se concebida a ação autônoma, como resultante de um processo de crescimento pessoal, deve-se concordar com Vygotski (2001) quando afirma que, sem a mediação, erros de interpretação podem prejudicar o processo de aprendizagem. Isso porque este não se restringe a um acréscimo de informação, mas enseja uma apropriação das motivações e valores mais ou menos implícitos nas atividades intencionalmente propostas.

A forma pela qual se processa o conhecimento adquire, desse modo, papel destacado, uma vez que contribui para a construção dos saberes, revelando as motivações éticas ou políticas que envolvem os atos humanos. Entretanto, o controle intelectual, desempenhado pelo domínio erudito, não se cumpre diretamente sobre os fenômenos. Segundo Latour (2000), ele se exerce sobre as inscrições que lhe servem de veículo. As inscrições, por sua vez, objetivadas no cotidiano em formas específicas, revelam a trajetória dessa construção coletiva que, entretanto, se individualiza em atos pessoais, específicos e expressivos.

\section{O CONTEXTO}

A tentativa de se explorar o contexto dessa construção coletiva, tanto nacional quanto internacional, revela um conjunto de forças que se cruzam e se contrapõem, especialmente mobilizadas pela busca de maior poder político. No cenário das bibliotecas acadêmicas, interconectado por redes de informação e cooperação, conjugam-se padrões e procedimentos, gerando-se habilidades de mediação a partir de demandas tão urgentes quanto complexas e heterogêneas.

O uso da Internet se expande a todos os setores da sociedade e o setor da informação e das comunicações é um dos mais dinâmicos da União Européia (UE) e do mundo. Atualmente, $90 \%$ das escolas e empresas da UE estão ligadas em linha e mais da metade da população é constituída por utilizadores regulares da Internet. "O setor da 
informação e das comunicações é um dos mais dinâmicos da União Européia e do mundo" (EUROPE DIRECT, 2006). A UE iniciou processo para promover o Espaço Europeu de Educação Superior (EEES) e neste espaço as bibliotecas universitárias são centrais. Ligadas às redes de informação, estão implementando serviços em linha aos cidadãos, tornando-se autênticos centros de aprendizagem.

Voltando-se o foco para o cenário nacional, observa-se uma realidade marcada por condições sócio-econômicas diversas. As bibliotecas acadêmicas começam a adquirir estrutura mais favorável à implementação de processos tecnológicos e isso decorre em grande parte dos esforços de avaliação das estruturas e recursos disponíveis quando da implantação de cursos ou instituições de ensino. Entretanto, os primeiros anos de escolaridade não preparam o grande contingente de pobres e excluídos, representantes das classes menos favorecidas da rede digital no Brasil e que virão a freqüentar, em extensão expressivamente reduzida, os bancos universitários. Segundo a União Internacional de Telecomunicações - órgão da ONU, "o país ocupa apenas a $71^{\mathrm{a}}$ posição entre as 180 economias mais adaptadas às novas tecnologias de comunicação" (SUAIDEN, 2006, p. 1).

Também são evidentes os contrastes regionais, pois, enquanto a região Sudeste apresenta os mesmos níveis de países ricos, grande parte da população do Norte e Nordeste jamais teve acesso a um computador. O fator que explica essa exclusão de parte importante da população na sociedade da informação é o nível educacional (SUAIDEN, 2006), embora haja propostas e estejam sendo implementados projetos para o desenvolvimento da economia digital, o aumento de investimento em P\&D e a redução do fosso digital.

Entre os acontecimentos a destacar nesse processo de integração de esforços que incluem as práticas de mediação e convergência, destacam-se as redes, ou estruturas que reúnem conservam, disseminam e fornecem informações, dando condições para a ampliação de oportunidades dos cidadãos. Elas têm sido compreendidas como tipos de sistemas de informação que podem adotar a forma de um serviço, um sistema ou uma combinação de ambos. Podem ser acessadas, tanto diretamente pelo usuário, quanto indiretamente, pelos sistemas on-line ou por meio de intermediários e integram-se aos esforços de mediação promovidos pelas bibliotecas e pelos atores no cenário acadêmico.

\section{MEDIAÇÃO E CONVERGÊNCIA}

No contexto em que se situam essas estruturas de informação, consideram-se, por um lado, a infra-estrutura eletrônica e de telecomunicações e, por outro, as comunidades que as caracterizam e que assumem papéis sociais, historicamente constituídos. Deles

resultam "culturas" diferenciadas, conceituadas como, a formação coletiva e anônima de um grupo social, representado por um conjunto de modos e de comportamentos criados, apreendidos e transmitidos entre os membros do grupo, em uma determinada sociedade ou nas instituições que o definem. (SOUZA, 2000, p. 19). 
Distinguem-se entre essas culturas, segundo Souza (2000), a acadêmica, a informacional e a telemática.

Integrantes dessa tríplice cultura e relacionados ao conceito de redes de informação, conceito que vem se transformando em função das inovações tecnológicas e das práticas sociais a ele integradas historicamente, situam-se os fenômenos da mediação e da convergência. .

Para este estudo, o termo mediação significa o fluxo de eventos entre a geração da informação por uma fonte emissora e a aceitação da informação pela entidade receptora. Como processo comunicacional, realiza uma das bases conceituais que se acredita seja o "cerne da Ciência da Informação: a geração de conhecimento no indivíduo e no seu espaço de convivência”. (BARRETO, 1999, p. 371).

Mesmo considerando-se esse sentido mais genérico dado ao termo mediação, ele enseja duas interpretações, a primeira, cuja ênfase recai no processo de aprendizagem e a segunda, com enfoque nos processos tecnológicos de suporte ao fenômeno. Assim, é visto como o "processo de divulgação científica mediante recursos educativos" (BARROS, 2005, p. 53) e sua prática demonstra que a capacidade de buscar informação e de interferir na construção de saberes estimula a criatividade e as transformações.

Ainda com essa ênfase, o processo de mediação aproxima-se, do ponto de vista de sua funcionalidade, a uma ativação da consciência. Isso porque é considerado um

trabalho analítico que consiste na distinção, na seleção e no julgamento, ou seja, em um discurso processual que nega as determinações imediatas e busca ativar o campo do sujeito, pois é nas relações intersubjetivas que a categoria de mediação se explica com mais clareza e contribui para a criação de processos de compreensão intersubjetiva das representações sociais através da argumentação e da manipulação cognitiva [...] (BRAGA, 2004, p. 1).

Concebida também como uma forma de energia, a mediação participa da ativação da inteligência coletiva, trabalhando com a informação e o conhecimento e, como defendem Tarapanoff, Suaiden e Oliveira (2002), agregando valor à primeira, facilitando o acesso e transferindo informação e conhecimento para todos.

Considerando-se que o conceito de mediação na área de BCI está intrinsecamente vinculado ao de redes e acesso à informação, pode-se afirmar que a Internet foi decisiva para o processo decorrente do conjunto de modalidades de apoio ao uso da Tecnologia da Informação e Comunicação (TIC). Assim acontece também em relação aos procedimentos de acesso a mecanismos de busca, à seleção, análise e síntese de conteúdos da informação, delineando-se uma interpretação de cunho tecnológico do termo, aproximada do processo de convergência. 
Da mesma forma, o termo mediática, se interpretado do ponto de vista pedagógico, refere-se à arte e à ciência das inter-relações entre os fenômenos humanos de percepção e expressão e aos sistemas digitais de informação. Se referenciado pela Metodologia da Mediação Dialética o processo origina-se na problematização de situações capazes de gerar contradições entre o ponto de partida (imediato) e o ponto de chegada (mediato) dos processos, possibilitando a aprendizagem por compreensão ou elaboração de sínteses cognitivas (saber aprendido). (ARNONI, 2004 apud ARNONI, 2006).

Já, sob um enfoque tecnológico, a mediática "estuda e estabelece as regras de desenho, produção, administração e difusão dos conteúdos interativos transportados por sistemas telemáticos" (CARTIER, 1992 apud SOUZA, 2000, p. 10). Refere-se ao uso da tecnologia na gestão da informação científica, em sua divulgação e na transformação do conhecimento em forma digital.

Como resultados de expressão social, o processo de mediação e a mediática, sob os dois enfoques que se analisem, contribuem para:

a) a solução de problemas;

b) o processo de identidade cultural;

c) a formação da cidadania;

d) a formação de usuários críticos, produtores e não simplesmente consumidores de conteúdos disponíveis pelas tecnologias de informação e comunicação. (SUAIDEN, 2006).

Esse modo de contribuição não se faz sem limitações ou problemas tais como a pouca familiaridade das pessoas com bases e redes de informação, a dificuldade em lidar com tecnologia, a confiança na busca realizada por pessoas especializadas como $o$ bibliotecário, o gestor da informação ou o informata, assim como a falta de tempo para buscas ou a falta de infra-estrutura adequada. Tais limitações pontuais são evidências da existência de "zonas de conflito introduzidas pela mediação das tecnologias de informação e comunicação nas bibliotecas universitárias, comuns no jogo da sociabilidade". (MORIGI; PAVAN, 2004, p. 117).

Entre as vantagens institucionais decorrentes das modalidades de mediação, destacamse a facilidade para o reconhecimento, acesso e uso de objetos da informação, a contribuição para o conhecimento de normas, procedimentos e habilidades dessa nova cultura que se impõe e a facilitação de práticas de referência virtual como links para outros sites (ask a service), com a utilização de comunidades de especialistas associados numa rede digital, para resposta a questões colocadas através da Internet (THE INTERNET, 2007). O correio de sugestões, o trânsito em outras bibliotecas, para acessar formulários de solicitações ou cadastramento e a utilização de outros serviços de alcance social estão entre as demais vantagens acrescidas pelo processo de convergência de mídias.

Das considerações sobre o alcance das práticas de mediação, deduz-se o impacto resultante dos avanços realizados no processo de convergência de várias tecnologias. $\mathrm{O}$ 
conceito de convergência digital surge da necessidade de representar um fenômeno que inclui o processo de criação de uma "solução única de infra-estrutura de transporte e distribuição de mídias e serviços. Nas telecomunicações, quando se fala em convergência, significa a redução para uma única conexão de rede, explorando ao mesmo tempo voz, vídeo e dados" (INSTITUTO BRASIL DE CONVERGÊNCIA DIGITAL, [2006]). Importa salientar que a temática relacionada ao fenômeno da convergência vem sendo discutida a partir dos anos de 1980, quando se reconheceu a importância da comunicação por computadores. As discussões originam-se, portanto, a partir da busca de integração tecnológica, processo subjacente, que permite a integração de dispositivos multimídia por meio de plataformas tecnológicas heterogêneas.

O conceito de convergência também é aplicado ao processo de formação de similaridades sucessivas entre tecnologias antes distintas, tecnologias que, segundo Valente (2006, p. 9), "estabeleceram no passado fronteiras claras entre os serviços que poderiam disponibilizar, mas atualmente compartilham de um mesmo ambiente digital".

Costuma-se citar a convergência entre informática, comunicações, produtos eletrônicos e entretenimento para ilustrar o fenômeno, embora o conceito seja bem mais abrangente, considerando-se as "heranças intelectuais" a serem administradas e integradas ao fenômeno. (PRAHALAD, 1999, p. 2).

Visualizam-se, graças ao exposto, três possibilidades de interpretação do termo. A primeira, relacionada à tecnologia digital; a segunda, às formas de organização das informações; e a terceira, que tem sido destaque na literatura de caráter marcadamente social e que neste artigo será vista mais detalhadamente, relacionada à aprendizagem. Com este enfoque específico, a convergência define-se como a conciliação de métodos e instrumentos nas práticas bibliotecárias, ou seja, ao resultado de aplicação de diversas mídias no ambiente acadêmico de produção, organização e tratamento para recuperação e disseminação de informações, especialmente voltado aos misteres do ensino superior, com apoio no desenvolvimento de redes de informação e cooperação entre bibliotecas acadêmicas.

Falar em convergência, argumenta Henriques (2006, p. 1), é referir-se à "integração tecnológica subjacente que permite a uma miríade de dispositivos multimédia comunicarem através de plataformas tecnológicas heterogêneas". Nessa integração, a interoperacionalidade é um conceito-chave, pois permite a comunicação inteligente entre dispositivos e outras aplicações em IP (Internet Protocol).

Conduzido por três tendências principais, o processo de convergência facilita a proliferação de informação digital, criando uma base comum para manusear diversos tipos de informação, promove a disseminação da conectividade entre as pessoas, permitindo reunir informações dispersas e alargar o valor e as possibilidades dos equipamentos para além das suas funcionalidades tradicionais e contribui para os constantes avanços na tecnologia. O novo conjunto tecnológico resultante, ou a resultar, passou a ser designado pela sigla ICT (Information and Communication Technologies), cujo conceito-chave em sua evolução é o de interoperacionalidade, a comunicação 
inteligente entre dispositivos e outras aplicações suportadas em IP (INSTITUTO BRASIL DE CONVERGÊNCIA DIGITAL, [2006]).

Nas telecomunicações, o termo convergência significa a redução para uma única conexão de rede que forneça todos os serviços com conseqüente economia de escala. (INSTITUTO BRASIL DE CONVERGÊNCIA DIGITAL, [2006]).

Entre os benefícios advindos dos processos voltados à convergência, a literatura de BCI reitera: a disseminação imediata e aprimoramento no processo informacional e, portanto, da expansão da oferta de produtos e serviços aos usuários; a distribuição de oportunidades e de valores; a criação de novas atividades profissionais e o acesso rápido e seguro à educação, saúde e justiça, entre outros direitos do cidadão.

No cenário específico das bibliotecas universitárias, os processos de aceleração da implantação dos novos meios e recursos tendem a modificar as ações e expectativas dos sujeitos, influenciando os saberes e transformando práticas culturais.

\section{SUJEITOS, SABERES E O PROCESSO DE MEDIAÇ̃̃O}

Se a vida dos cidadãos é afetada direta ou indiretamente pelas condições econômicas, com o advento das vantagens oferecidas pela tecnologia supõe-se a ampliação dos direitos e das oportunidades pessoais e coletivas, dilatando-se as estruturas limítrofes, em meio à diversidade de oportunidades e expectativas. $\mathrm{O}$ foco nesses sujeitos e nas mudanças de suas vidas requer um especial recorte concernente às relações que se estabelecem no especial cenário da biblioteca universitária. Os sujeitos interatuantes nesse processo são, por um lado, alunos, bibliotecários, professores e especialistas e, por outro, as instituições universidade e biblioteca.

Os alunos tornam-se elementos ativos no processo educacional quando efetivamente incluídos na esfera das atuais tecnologias de informação. Se antes do aperfeiçoamento da infra-estrutura tecnológica as bibliotecas acadêmicas já representavam um papel essencial ao desenvolvimento das atividades de ensino, pesquisa e extensão, hoje, ultrapassadas as discussões dicotômicas como a que opõe acervo e acesso, revelam-se práticas de apoio ao usuário em prol da autonomia e da segurança de busca. Destacamse também no cenário, embora com atuação pouco expressiva diante das possibilidades que apresenta a biblioteca universitária para sua ação educativa, os professores, sujeitos mediadores por excelência na construção do conhecimento, líderes, tutores e coordenadores na seleção de conteúdos e de práticas e, de modo especial, organizadores de informações e de atividades didáticas.

De modo especial a função mediadora se adequa à conjuntura atual, impondo também formas alternativas de interação entre o bibliotecário e o aluno, o bibliotecário e o professor e, o que emerge como a mais completa modalidade de construção, o trabalho conjunto e intencional entre as três categorias. 
Assim desenvolvem iniciativa pessoal e grupal, na busca de conteúdos e construção de saberes, além de definirem problemas para iniciar suas pesquisas e proporem suas soluções. Como conseqüência, novas práticas se apresentam para as profissões cujo objeto é a informação. Elas se manifestam sob formas de sociabilidade, alterando as representações sociais dos profissionais e suas práticas de atuação. (MORIGI; SILVA, 2005).

Entretanto, as transformações das práticas, definidas e redefinidas pelas estruturas que se renovam, impõem aos profissionais da informação algumas condições; entre elas, a consciência de que a mediação não substitui o mediador, de que o trânsito em comunidades especializadas em áreas correlatas e comunidades não especializadas é fundamental e, de modo especial, de que a comunicação como elemento formativo do educador é estratégica.

Entre os desafios enfrentados pelos profissionais da informação, a partir da convergência das mídias, sobressaem aqueles voltados à construção epistêmica. Estes exigirão atenção especial às relações teórico-práticas, ao planejamento e avaliação das atividades voltadas aos usuários, aos usos das tecnologias de informação, à capacidade de interpretar e operar um conjunto de informações, especialmente de referência virtual, utilizando-se das mais recentes tecnologias e, especialmente, à construção de pontes e redes. Esse esforço pessoal e institucional constitui-se na prática de mediação com apoio na convergência digital.

Também exercitam suas atividades no ambiente institucional, os especialistas em domínios específicos do saber como administradores e gestores, comunicadores, informáticos, lingüistas, economistas, psicólogos e antropólogos. De todos esses sujeitos é demandada a disposição de aprender e de se adaptar ao cenário no qual desempenham seus papéis, mediando conhecimentos em processos transdisciplinares.

É a consciência coletiva desse potencial mediador o elemento chave para que a biblioteca universitária se torne agente vivo e atuante nas práticas institucionais de construção de saberes. O exercício do papel mediador nesse processo permite a construção de uma cultura própria, formada por um conjunto de hábitos e normas específicos e gerada a partir da possibilidade de convergências de mídias e estratégias de comunicação.

As práticas dos sujeitos, nesse contexto acadêmico, dependem, portanto, da capacidade de antecipar, planejar e reagir às mudanças e de promover parcerias inovadoras que neutralizem a rigidez de hierarquias e limites de ação. Dessa forma, é possível catalisar a criatividade a partir das relações dos sujeitos em cooperação para a criação do conhecimento. A visualização das relações entre atores no ambiente institucional permite a avaliação de seus elementos constituintes, mobilizados pela mediação e por meio de recursos convergentes para o compartilhamento da informação e do conhecimento. Por certo que o sucesso das práticas informacionais é facilitado pela convergência digital, já que representado pela união das multimídias e multimeios, entretanto não é suficiente sem os sujeitos mediadores. A orientação e a implementação 
de atividades que transformem as bibliotecas em espaços maximizados de aprendizado é que as qualificam como mediadoras desse processo (DIAS et al., 2004).

\section{FORMAS E RELAÇÕES}

Para que se analise uma realidade concreta, além dos acontecimentos, cenários e atores, pessoais ou institucionais, é importante que se identifique as formas e relações de força, o jogo político a partir dos diferentes pontos de vista e dos móveis econômicos das classes e das frações de classe que disputam entre si. Assim, focando as práticas de mediação e convergência, identificam-se as forças interferentes na conjuntura e no desenvolvimento dos processos de trabalho e aprendizagem, que representam interesses e podem ser evidenciadas no esforço analítico para desvendar as relações e as condições sem as quais é impossível transformar a realidade.

Se a participação mais efetiva das bibliotecas em redes é meio de agilizar seus serviços e compartilhar recursos, utilizando-se de forma inteligente da Internet (DUMANS, 1993), vale refletir, portanto, sobre as relações possíveis nesse contexto interativo em que os interesses em disputa expressam e tornam compreensíveis relações de força, tendências, sujeitos e disputas visíveis no jogo das aparências.

Iniciando-se pelas relações de confronto, percebe-se no cenário, tanto internacional quanto local, as forças existentes entre a globalização capitalista e os excluídos, entre políticas antagônicas, representadas por facções ou grupos de poder produtores de tecnologias de informação, entre modelos de distribuição mais ou menos democratizantes e entre grupos de poder econômico ou político com influência nas decisões. A estrutura assim constituída e fortalecida serve à indústria das telecomunicações, a fim de diminuir custos, ampliar mercados e "democratizar" as informações (XAVIER, 2006).

Nessa conjugação de forças, são visíveis as relações de domínio da informação exercido pelo capital constituinte das estruturas, dos aparelhos e da tecnologia, da presença de grupos políticos influentes no campo da informação, ou de predomínio de decisões de determinados atores sobre outros.

Por outro lado, vislumbram-se oposições, resultantes das desigualdades e das formas hierárquicas vigentes nas relações institucionais e empresariais, relações de domínio da informação exercido pelo capital constituinte das estruturas, dos aparelhos e da tecnologia, ou ainda, relações de subordinação, decorrentes da pobreza, das desigualdades de força política e econômica e da ideologia do fato consumado. Agravadas pelas condições sociais, econômicas ou culturais e as decisões políticas autoritárias, essas relações também se exercem em virtude dos hábitos e condições impostas pelo dominante como forma de controle. Os negócios da área de TIC, por exemplo, são impulsionados pela disponibilidade de tecnologia e pela demanda de usuários habituados com as vantagens da era digital e de profissionais capacitados. 
Travestidas de rótulos como mediação e convergência, formas de domínio arriscam seu jogo e, como diria Morin (1996, p. 109), com a tecnologia "inventamos modos de manipulação novos e muito sutis, pelos quais a manipulação é exercida sobre as coisas", implicando a "subjugação dos homens pelas técnicas de manipulação".

Essas relações verificam-se na conjuntura em que formas excludentes de produção e reprodução de bens coexistem com as amplas possibilidades dos processos de convergência e mediação, em seus domínios e dimensões específicos.

Esses processos também presenciam, por outro lado, relações de cooperação entre atores e instituições, de modo mais evidente entre bibliotecários, professores e alunos, entre bibliotecas, redes de informação e redes sociais e desses atores entre si.

Uma das formas de evidência da inter-relação entre atores para demonstrar a complementaridade e equilíbrio de suas práticas pode ser visualizada em estudos sobre redes sociais, como ilustra o trabalho de Alcará e outros (2006). Os resultados do estudo indicam que as redes sociais colaboram para o fortalecimento da cultura organizacional, voltada para o compartilhamento da informação e do conhecimento. O mapeamento das redes possibilita rastrear os fluxos da informação, permitindo a identificação da estrutura informacional que permeia o ambiente da organização.

Segundo essa concepção, as redes sociais também contribuem para a compreensão e elaboração de práticas fundamentadas na mediação e na convergência, para o funcionamento do contexto institucional. Nelas predominam relações de igualdade possível entre educadores, os bibliotecários considerados como tal, e alunos, integrados em favor da educação, entre educadores e especialistas como mediadores no acesso à informação e às TICs.

É necessário levar em conta, sobretudo, que as relações de força sofrem mudanças permanentemente, pois o poder desloca-se em função de planejamentos e decisões políticas nos diferentes níveis. Assim, em oposição ao estado de desequilíbrio de forças, articulações são possíveis, especialmente se levada em conta a convergência tecnológica enquanto objeto privilegiado da cultura. E dela usufruindo, a mediação exerce influência sobre a cultura institucional, podendo neutralizar o processo reprodutor de desigualdades. A convergência digital, portanto, pode alterar as relações de poder entre os parceiros, instituições e grupos, redefinindo estruturas e domínios e o próprio processo de mediação.

Analisar a conjuntura, em determinado momento histórico, em uma determinada correlação de forças é, portanto, uma ação fundante para o diagnóstico e a tomada de consciência da realidade concreta.

\section{ARTICULAÇÃO}

A análise, embora passível de estudos mais intensivos, permite ressaltar que o compartilhamento da informação, fortalecido pelos fenômenos de mediação e 
convergência, verifica-se em contexto constantemente modificado por transformações. Assim como os textos agem sobre o mundo e circulam em situações, práticas e instituições que nos ligam a situações (LATOUR, 2000), as bibliotecas, ao extraírem saberes e cultura da sociedade, transformam-se e transformam os sujeitos, relacionandoos numa espécie de jogo dialético entre o instituído e o instituinte.

Essa força de construção e reconstrução pode acompanhar o avanço das TICs integradas nos processos de mediação e convergência, para melhor usufruto de suas benesses e fortalecimento da idéia de uma cultura investigativa na biblioteca universitária. É possível construir-se essa cultura por meio do desenvolvimento de conteúdos e objetos de informação e do reconhecimento da importância estratégica dos aspectos que se concentram na formação de modelos digitais de informação e de comunicação.

Assim, estabelecidas, formando estruturas de informação e comunidades participativas, as bibliotecas são capazes de combinar e mediar interesses individuais e coletivos. Nessa direção, esforços de ampliação de grupos de trabalhadores da informação poderão modificar as relações de produção, incluindo-se especialistas nas decisões políticas. Essa percepção está presente no texto em que Marcondes e Gomes (1997) argumentam ser a conexão das bibliotecas brasileiras à rede motivo para que se exija a capacitação de profissionais da informação, dado o impacto das TICs, em especial da Internet, sobre as bibliotecas brasileiras e o papel destas na promoção do uso democrático da Rede.

Essa exigência justifica-se, pois as bibliotecas passam a ser organizações que interagem constantemente com o meio ambiente e a cultura, requerendo dos bibliotecários conhecimentos e habilidades específicas para atuar em contexto especialmente voltado ao ensino e à pesquisa, estimulado pelas redes de informação.

Os argumentos tecidos na literatura levantada sugerem que, na conjuntura acadêmica, a estreita e necessária relação entre os processos de mediação e convergência permitem a ação intencional dos sujeitos individuais e coletivos. A proposta de desenvolvimento de competências para a mediação e comunicação digital da informação deve contribuir, portanto, para dotar os participantes de elementos de conciliação intencional entre os elementos vocacionais de uma biblioteca universitária.

Mas como bem lembrou o sábio Unamuno (1981), para convencer é preciso ter a justiça e a razão ao seu lado. E para uni-las, a grande tarefa é a mobilização para a crítica e a construção do conhecimento. Nessa tarefa a utilização dos métodos, instrumentos e estratégias; o reconhecimento e análise de estruturas, contextos, instituições e atores participam ativamente, avaliando, propondo e equilibrando o potencial de democratização com as estruturas do sistema cultural e educacional brasileiro.

Desse modo, o comprometimento e os sinais de vida perceptíveis nas práticas, embora repletos de sentidos e com dinâmicas próprias, apresentam uma lógica construída com os sentidos comuns dos acontecimentos. Essa lógica atribui fóruns especiais às bibliotecas acadêmicas, não apenas mediadoras, mas fenômenos culturais construídos 
na sua exposição e por suas transformações. Como espaços de conservação, só fazem sentido pela qualidade dos saberes que recolhem e não pela quantidade dos títulos que conservam e enquanto espaços de transformação têm o poder de conjugar a cultura investigativa para a construção dos saberes. Portanto, não apenas fazem parte dessa cultura, mas podem ser consideradas como sujeitos de sua construção.

\section{REFERÊNCIAS}

ALCARÁ, Adriana R. et al. As redes sociais como instrumento estratégico para a inteligência competitiva. Transinformação, Campinas, v. 18, n. 2, p. 143-153, maio/ago. 2006.

ARNONI, Maria Eliza B. Metodologia da Mediação Dialética: uma proposição de aula interessante. São Paulo: Teia do Saber/IBILCE-UNESP, 2006. 6 Slides. Disponível em: <http://www.ibilce.unesp.br/teia2006/aula\%20destaque\%20lixo.ppt $>$. Acesso em: 10/10/2006.

ASSMANN, Hugo. A metamorfose do aprender na sociedade da informação. Ciência da Informação, Brasília, v. 29, n. 2, p. 7-15, 2000.

BARRETO, Aldo de A. Os destinos da Ciência da Informação: entre o cristal e a chama. Informação \& Sociedade: Estudos, João Pessoa, v. 9, n. 2, p. 371-382, 1999.

BARROS, Daniela M. V. Competência virtual para a mediação da informação e do conhecimento (virtual literacy). ETD - Educação Temática Digital, Campinas, v. 6, n. 2, p. 53-62, 2005.

BIRDSALL, Willian F. Uma economia política da biblioteconomia? Perspectivas em Ciência da Informação, Belo Horizonte, v. 10, n. 1, p. 86-93, jan./jun. 2005.

BRAGA, William D. Mediação e processos de compreensão intersubjetiva das representações sociais do trabalho. DataGramaZero, Rio de Janeiro, v. 5, n. 3, 2004. CHARLOT, Bernard. Da relação com o saber: elementos para uma teoria. Porto Alegre: Artes Médicas, 2000. 93 p.

DIAS, Maria Matilde K. et. al. Capacitação do bibliotecário como mediador do aprendizado no uso de fontes de informação. Revista Digital de Biblioteconomia \& Ciência da Informação, Campinas, v. 2, n. 1, p.1-16, 2004.

DUMANS, Maria L. F. Internet: novas perspectivas para a biblioteca no ciberespaço. Transinformação, Campinas, v. 5, n. 1/2/3, p. 72-79, 1993. EUROPE DIRECT. Em poucas palavras, maio, 2006. Disponível em: $<$ http://www.europedirect.uac.pt/noticias/ver.php?id=25>. Acesso em: 10/08/2007. FURNIVAL, Ariadne Chloé. Redes para cooperação internacional: uma janela de oportunidade para os países recém industrializados? Perspectivas em Ciência da Informação, Belo Horizonte, v. 3, n. 2, p. 115-123, 1998.

GONZÁLEZ DE GÓMES, Maria Nélida. A informação: dos estoques às redes. Ciência da Informação, Brasília, v. 24, n. 1, p. 77-83, 1995.

GRAMSCI, Antonio. Os intelectuais e a organização da cultura. 6. ed. Rio de Janeiro: Civilização Brasileira, 1988. 244 p. (Filosofia, 48).

HENRIQUES, José. Compuquali na Imprensa. Revista Upgrade, Lisboa, n. 9, fev. de 2006. Disponível em: $<$ http://www.compuquali.pt/PressNews/060201-UPGnova\%20era\%20nas\%20TIC.htm>. Acesso em: 10/10/2006. INSTITUTO BRASIL DE CONVERGÊNCIA DIGITAL. A revolução digital leva à 
convergência. São Paulo, [2006?]. Disponível em:

$<$ http://www.ibcd.com.br/conv_digital.htm>. Acesso em: 10/10/2006.

LATOUR, Bruno. Redes que a razão desconhece: laboratórios, bibliotecas, coleções. In:

BARATIN, Marc; JACOB, Christian (Org.). O poder das bibliotecas: a memória dos livros no Ocidente. Rio de Janeiro: EDUFRJ, 2000. 351 p.

MARCONDES, Carlos H.; GOMES, Sandra L. R. O impacto da Internet nas bibliotecas brasileiras. Transinformação, Campinas, v. 9, n. 2, p. 57-68, 1997.

MARTELETO, Regina Maria. Análise de redes sociais: aplicação nos estudos de transferência da informação. Ciência da Informação, Brasília, v. 30, n. 1, p. 71-81, 2001.

MORIGI, Valdir José; PAVAN, Cleusa. Tecnologias de informação e comunicação: novas sociabilidades nas bibliotecas universitárias. Ciência da Informação, Brasília, v. 33, n. 1, p. 117-125, 2004.

MORIGI, Valdir José; SILVA, Magali L. Paradigma tecnológico e representações sociais dos bibliotecários sobre seu perfil e suas práticas no contexto da sociedade da informação. Informação \& Sociedade Estudos, João Pessoa, v. 15, n. 1, 2005.

MORIN, Edgar. Ciência com consciência. Rio de Janeiro: Bertrand Brasil, 1996. ODDONE, Nanci. O profissional da informação e a mediação de processos cognitivos: a nova face de um antigo personagem. Informação \& Sociedade Estudos, João Pessoa, v. 8, n. 1, p. 25-41, 1998.

PRAHALAD, C. K. Reexame de competências. Revista HSM Management, Barueri, SP, ano 3, n. 17, nov./dez. 1999. Disponível em:

$<$ http://www.unicap.br/marina/reexame.html>. Acesso em: 10/10/2006.

SANTOS, Plácida L. V. A. C.; MARTINEZ, Vinício C. A rede e o conhecimento.

Informação \& Informação, Londrina, v. 5, n. 2, p. 111-124, 2000.

SOUZA, Clarice M. de. Convergência: um fator de qualidade nas redes acadêmicas. In: SEMINÁRIO NACIONAL DE BIBLIOTECAS UNIVERSITÁRIAS, 11.,

Florianópolis, abr. 2000. Anais... Florianópolis: UFSC, 2000.

SOUZA, Herbert José de. Como se faz análise de conjuntura. 25. ed. Petrópolis:

Vozes, 2004.

SUAIDEN, Emir. O Brasil e o acesso às novas tecnologias. Brasília: IBICT, 2006.

Disponível em: $<\mathrm{http}: / / \mathrm{www}$. ibict.br/noticia.php?page=5\&id=287>. Acesso em:

10/10/2006.

TARAPANOFF, Kira; SUAIDEN, Emir José; OLIVEIRA, Cecília L. Funções sociais e oportunidades para profissionais da informação. DataGramaZero, Rio de Janeiro, v. 3, n. 5, 2002.

THE INTERNET PUBLIC LIBRARY. Want to know about the IPL's "Ask a

Question" Service?, 2007. Disponível em:

$<$ http://www.ipl.org/div/askus/refservice.html>. Acesso em: 10/10/2007.

VALENTE, Jarbas José. VoIP e Internet no Brasil: que nível de convergência é esperado. Brasília: ANATEL, 2006. Disponível em:

$<\mathrm{http}$ //www.anatel.gov.br/acontece_anatel/palestras/VoIP_UnB.pdf $>$. Acesso em: 30/03/2007.

UNAMUNO, Miguel de. EI otro, el hermano Juan. 5. ed. Madrid: Espasa-Calpe, 1981. $144 \mathrm{p}$.

VYGOTSKI, L. S. Obras escogidas. 2. ed. Madrid: A. Machado Libros, 2001. 484 p. 
XAVIER, Rodrigo. Convergência digital. Vôo Subterrâneo, set. 2006. Disponível em: $<$ http://voosubterraneo.blogspot.com/2006/09/convergncia-digital.html >. Acesso em: $10 / 10 / 2006$.

\begin{abstract}
This work analyses the possibilities of an informational culture in Brazilian university libraries, turned to the construction of a favorable environment for the formation of knowledges, and it establishes five categories related to the highlighted problem: the context; the phenomena of mediation and convergence as related to information webs; the subjects in the process; the power relations; and the articulation among those factors. It concludes that libraries have the ability to conjugate the several investigation practices in the construction of knowledges, not only as parts of the university culture, but rather as subjects of its construction.
\end{abstract}

KEYWORDS: University libraries. Mediation. Convergence. Information webs.

Originais recebidos em: 14/11/2007

Texto aprovado em: 13/03/2008 